\title{
SPONTANEOUS MAMMARY TUMORS IN BITCHES
}

Eman, A. Abdel-Aziz

Dept. Pathology, Fac. Vet. Med., Kafr El-Sheikh, Tanta Univ.

\section{ABSTRACT}

Spontaneous canine mammary tumors were studied in bitches of different breeds at an age ranging from 6-10 years. Twenty-two bitches were positive to mammary tumors and eight were negative. The mammary tumors were classified into three groups. The first group contained fibrosarcoma, which was detected in 9 out of 22 bitches. In this tumor, the mitotic activity was not obvious but the malignancy of the tumor was based on high cellularity, polymorphism and hyperchromatic nuclei. Some areas of the tumor showed metaplastic changes in which the fibrocytes showed the feature of chondrocytes. The second group of mammary gland tumors was classified as cystic adenocarcinoma, which was detected in 6 out of 22 bitches. In this tumor, there were dilated cysts, its wall was lined by cuboidal or columnar epithelial cells and the cysts were empty or filled with protein rich fluid or necrotic debris. In addition, in some areas of the tumors, the lactating acini may show degenerative and hyperplastic changes. The third group was classified as adenofibrosarcoma and was detected in 7 out of 22 bitches. The tumors showed proliferation of neoplastic cells of the acini and ducts and formed cystic and papillary structures, which were separated by highly proliferated fibrous strands.

\section{INTRODUCTION}

It is arguable that the dog suffers a higher incidence of neoplasia than any other animal species including man. The recorded frequency of one such tumor, that of mammary gland, is 3-4 times higher in the bitch than it is in women. It has been suggested that bitch mammary tumor might be a highly suitable model for human breast cancer (Raynaud et al.,1981), and may lead to improved methods of treatment in human breast cancer (Owen, 1979). 
Previous studies have intimated that mammary tumors in the dog, although three times more prevalent, resemble those in man in several ways: they are spontaneous, they have several histological types in common with human tumors (Strandberg and Goodman, 1974; Owen, 1979), they also contain estrogen receptors(Evans and Pierrepoint, 1975; Monson et al., 1977) with an incidence comparable to estrogen receptors in human tumors (Hamilton et al., 1977) and they can contain progestin receptors (D'Arville and Pierrepoint, 1975). In the light of this evidence, it has been suggested that canine mammary tumors can be considered a suitable model for human breast cancer.

The aim of the present work was to study the spontaneous mammary tumors in bitch and their microscopical structure.

\section{MATERIAL AND METHODS}

\section{Material:}

Tissue specimens were collected from 30 bitches of different breeds at 6-10 years old. Eight cases were free from mammary tumors while twenty-two showed mammary tumors. Specimens of tissue were collected, trimmed of fat and connective tissue and then fixed in formalin solution for histopathological examination. Fixed tissue specimens were then subjected for the routine technique of paraffin embedding. Paraffin sections of 3-5 microns thick were prepared and stained with hematoxylin and eosin (Bancroft and Stevens, 1990).

\section{RESULTS}

Spontaneous mammary tumors were found in twenty-two cases ranging from 6-10 years old of different breeds.

\section{Histopathological findings:}

All tumors showed multifocal lesions. The first group consisted of fibrosarcomas which were detected in 9 out of 22 bitches (Fig. 1-6). The tumor was composed of proliferating fibroblasts arranged in interlacing $\overline{\text { Kafr El-Sheikh Vet. Med. J. Vol. } 3 \text { No. } 1 \text { (2005) }}$ 
bundles formed of collagen fibers (Fig. 1, 2). Although mitotic figures were not obvious, the malignancy of the tumor was based on prominent high cellularity, certain degree of polymorphism and hyperchromatic stain of the nuclei (Fig. 3). The tumor may appear rich in collagen fibers bundles embedded in tumor matrix and were poor in cells (Fig. 4). In some cases of tumor, the fibrocytes had feature of metaplastic changes in which the cells showed the structure of chondrocytes (Fig. 5, 6).

The second group of tumors was classified as cystic adenocarcinoma which was detected in 6 cases. The tumors consisted of dilated cystic structures, the wall of cysts consisted of either condensed fibrous structures or single layer of epithelial cells ranging from cuboidal to columnar cells (Fig. 7, 8). In some areas of tumors, there were secondary papillary projections protruding into cystic spaces. The cysts may be empty or filled with protein rich fluid or necrotic desquamated epithelial cells and debris (Fig. 9, 10, 11). Lactating acini in one of the tumors showed degenerative changes (Fig. 12). In other areas, the wall of these lactating ducts may show hyperplastic changes (Fig. 13). The lymph spaces in some tumors were thrombosed (Fig. 14).

The third group of tumor was classified as adenofibrosarcoma and was detected in 7 cases. The neoplastic cells of the acini and duct were either proliferated with cystic formation or having papillary appearance. These structures were separated and surrounded by highly proliferated fibrous strands running in various directions (Fig. 15, 16).

\section{DISCUSSION}

Examination of mammary glands of 30 bitches ageing 6-10 years of different breeds revealed the occurrence of tumors in 22 cases. The tumors were classified as fibrosarcomas(9cases),cystic adenocarcinomas( 6 cases) and adenofibrosarcomas ( 7 cases).

The present results of spontaneous mammary tumors in bitch were nearly similar to those recorded by Lucilia and Nune (1981), Eskens 
(1983), Yancher et al. (1988) and Penazze et al. (1989) who described spontaneous mammary gland tumors in bitches as adenocarcinoma, fibrosarcoma and mixed tumors. Jubb et al. (1993) mentioned that mixed mammary gland tumors, may contain other tissue elements as bone and cartilage. They stated that this type of tumors results from predominant proliferation of myoepithelial cells which tend to become embedded in chondrial matrix. The bone in the tumors appeared to be formed by endochondral ossification of preformed cartilage or by intermembranous ossification in the connective tissue of the tumor. This finding is similar to what has been described in some types of tumors in the present study in which fibrocytes had the feature of metaplastic changes and the cells showed the feature of chondrocytes; however, bony tissues were not seen. This difference may be related to the breed. Other factors which may affect the incidence of spontaneous mammary tumors in bitches are age, breed and health status. The most suitable age for the appearance of mammary tumors was 7-10 years (Owen, 1979 and Porle et al., 1980), this is in parallel to the present study where spontaneous mammary gland tumors appeared at 6-10 years old. Cotchin (1958) detected spontaneous mammary tumors, however, at 2-3 years old as hyperplastic alveolar nodules and considered them as evidence of preneoplasia. This difference may be related to the breed; the author used certain strain of bitches (Beagles breed). It can be mentioned, thus, that the difference in histological types of mammary tumors in bitch may be related to age and breed. This finding is confirmed by Dorn et al. (1968) who reported that genetics plays an important role in the development of mammary gland tumors in bitches.

The present result may indicate that bitch mammary tumors might be highly suitable model for human breast cancer. In general, mammary tumors in women are diagnosed at about 10 years, i.e. at $4 / 5^{\text {th }}$ of the mean life span of bitch which corresponds to a time when incidence of breast cancer in women is high (approximately 60 years). This is confirmed by Motel et al. (1997) who reported that canine tumors can constitute a useful model for the study of human breast cancer and may lead to improved methods of its treatment. 


\section{DESCRIPTION OF FIGURES}

Fig. $(1,2)$ : Mammary gland of bitch, 7 years old. Fibrosarcoma, proliferating fibroblasts arranged in interlacing bundles and embedded in collagen fibers (H\&E, X200).

Fig. (3): Mammary gland of bitch,8 years old.Fibrosarcoma, the tumor shows high cellularity, certain degree of polymorphism and hyperchromatic stain of nuclei (H\&E, X200).

Fig. (4): Mammary gland of bitch, 9 years old. Fibrosarcoma, the tumor is rich in collagen fiber bundles consisted in tumor matrix and poor in cells. (H\&E, X200).

Fig. (5): Mammary gland of bitch, 9 years old. Fibrosarcoma, fibrocytes showing the feature of metaplastic changes in which the cells showed the features of chondrocytes. (H\&E, X200).

Fig. (6): As Fig. (5), (H\&E, X400).

Fig. $(7,8)$ : Mammary gland of bitch, 7 years old. Cystic adenocarcinoma. The tumor consisted of dilated cystic structures, the wall of the cysts consisted of single layer of epithelial cells ranging from cuboidal to columnar cells. There were secondary projections protruding into cystic spaces. (H\&E, X200).

Fig. (9): Mammary gland of bitch, 7 years old. Cystic adenocarcinoma. The cysts were filled with protein rich fluid. (H\&E, X200).

Fig. $(10,11)$ : Mammary gland of bitch, 8 years old. Cystic adenocarcinoma. The cysts were filled with desquamated epithelial cells and debris. (H\&E, X200).

Fig. (12): Mammary gland of bitch, 8 years old. Cystic adenocarcinoma. Degenerative changes of lactating acini (H\&E, X200).

Fig. (13): Mammary gland of bitch, 9 years old. Cystic adenocarcinoma. The wall of lactating ducts show hyperplastic changes. (H\&E, X200).

Fig. (14): Mammary gland of bitch, 9 years old. Adenocarcinoma. Lymph spaces showing thrombosis. (H\&E, X200).

Fig. $(15,16)$ : Mammary gland of bitch, 10 years old. Adenofibrosarcoma. The neoplastic cells of the acini and ducts were either proliferated with cystic or papillary appearance. These structures were separated by fibrous strands which were running in various directions. (H\&E, X200).

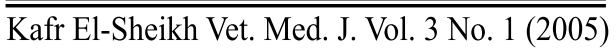



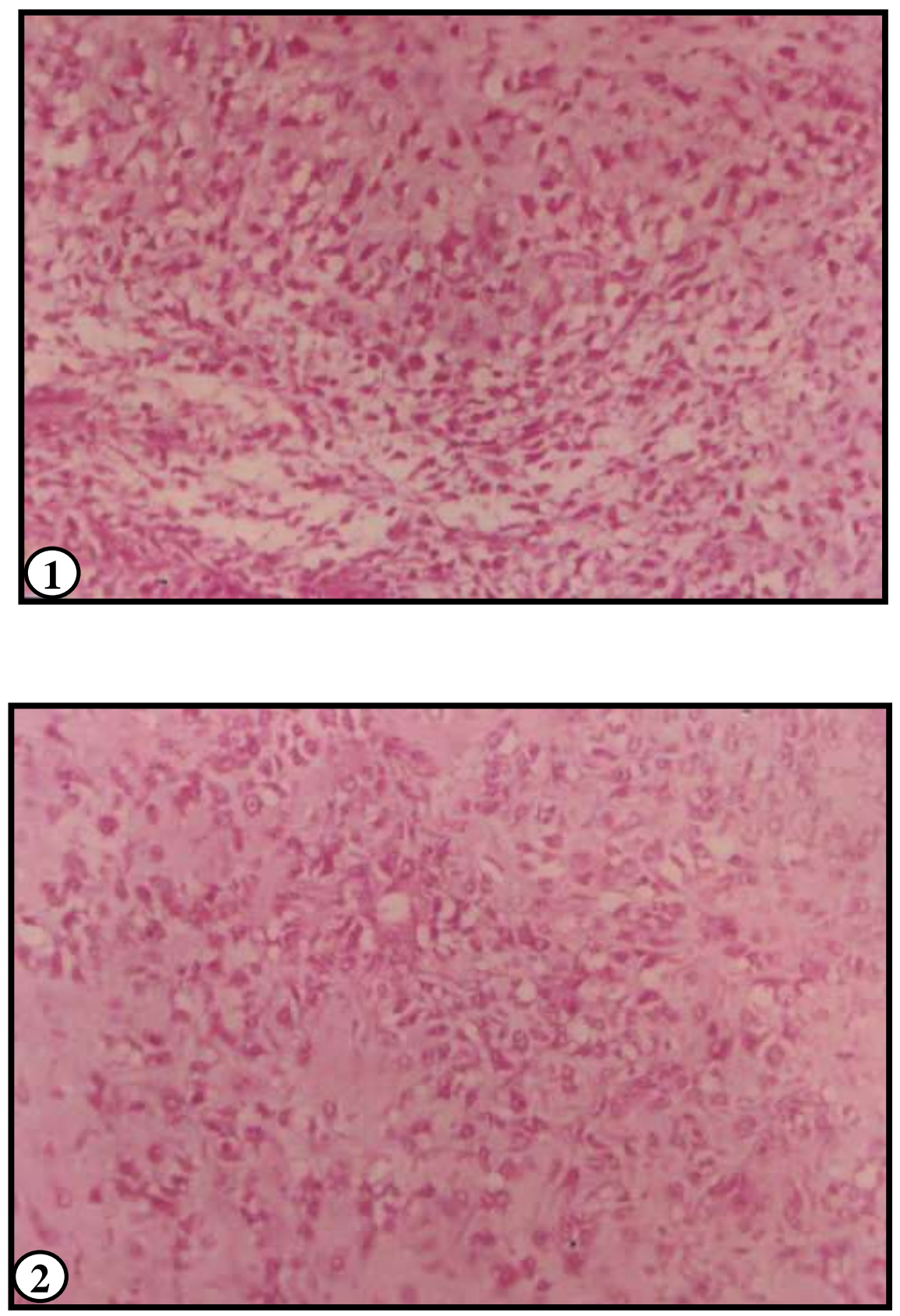

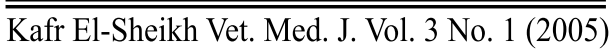



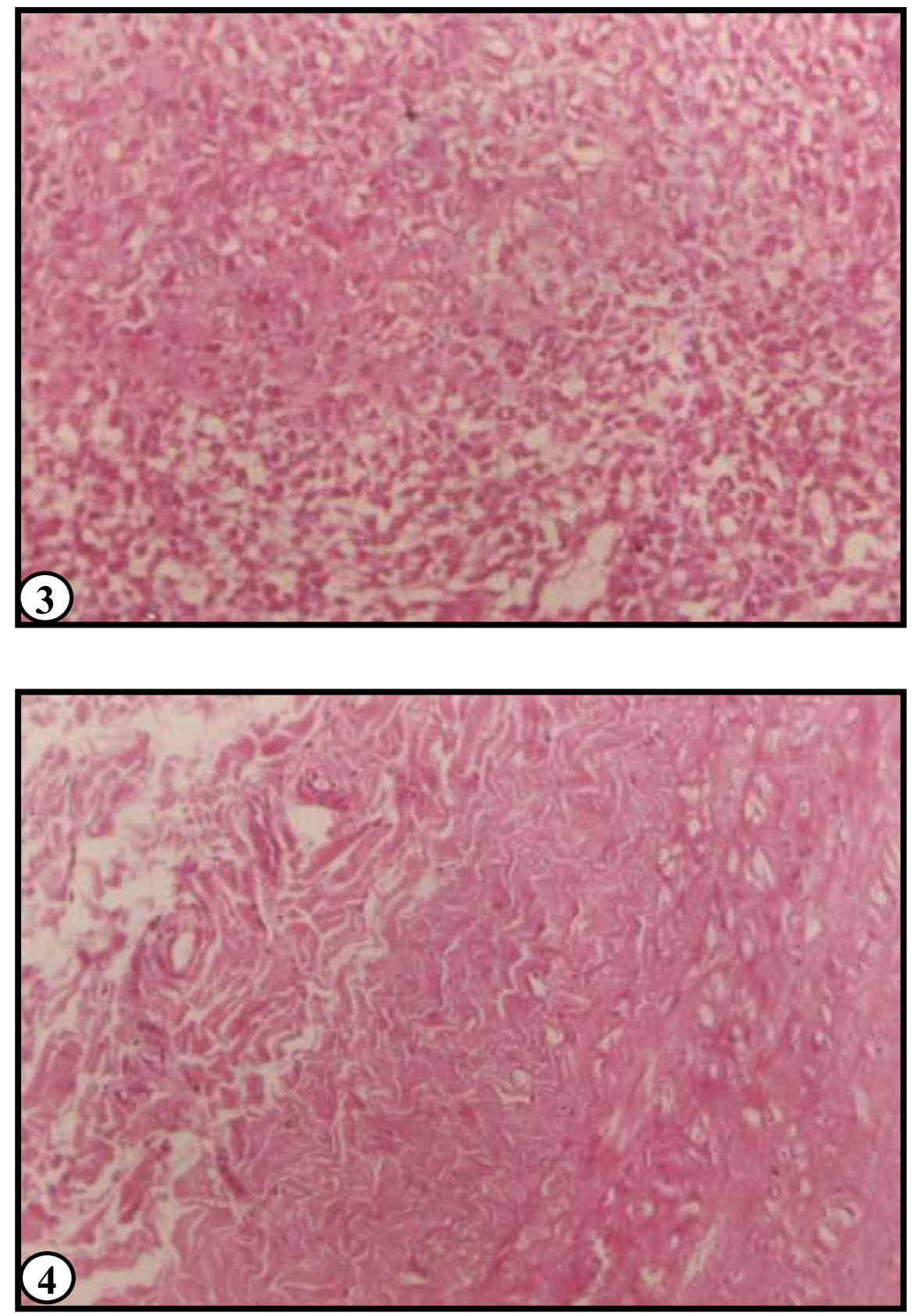

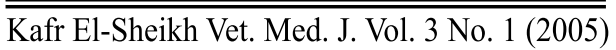



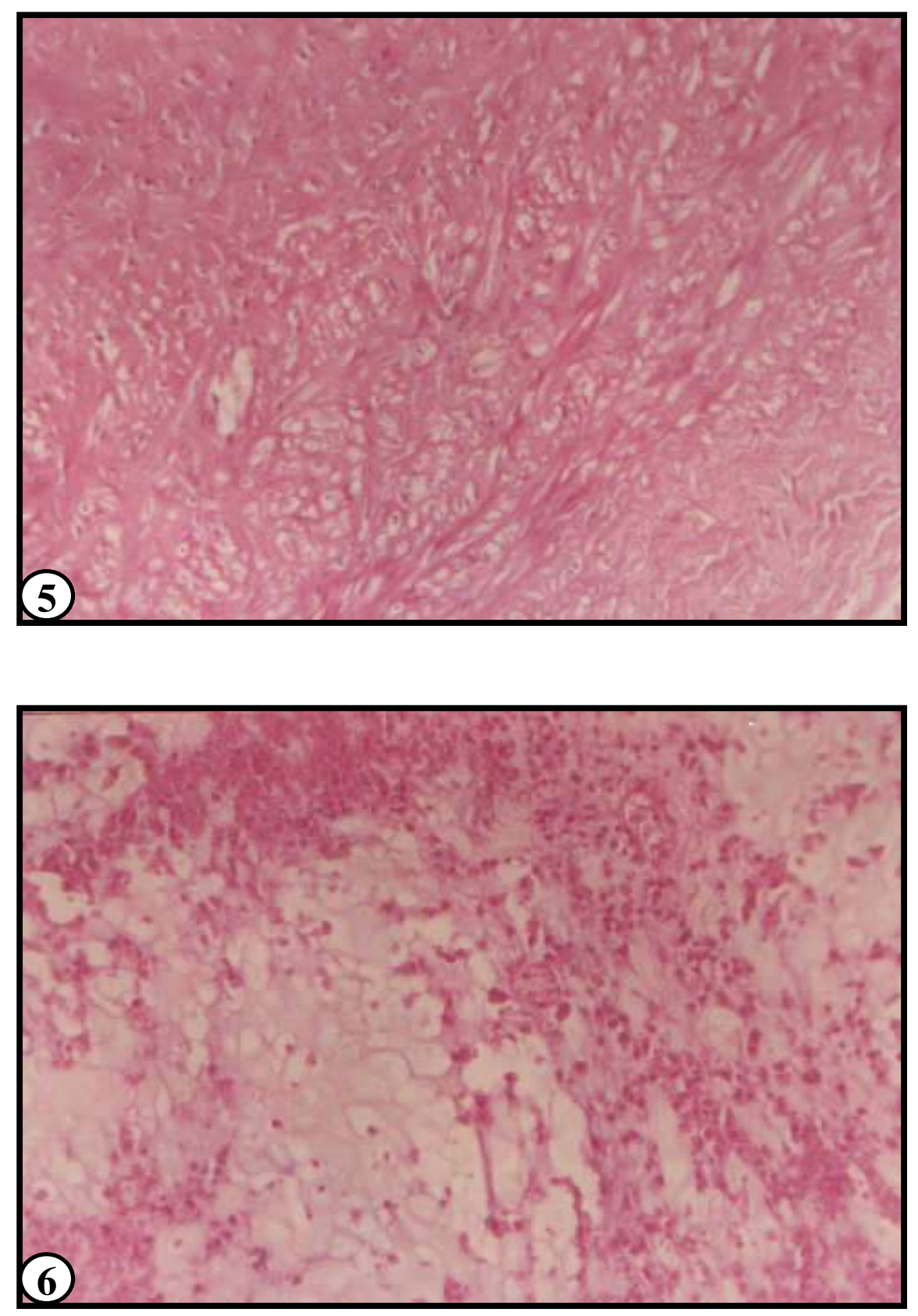

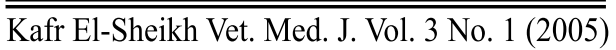



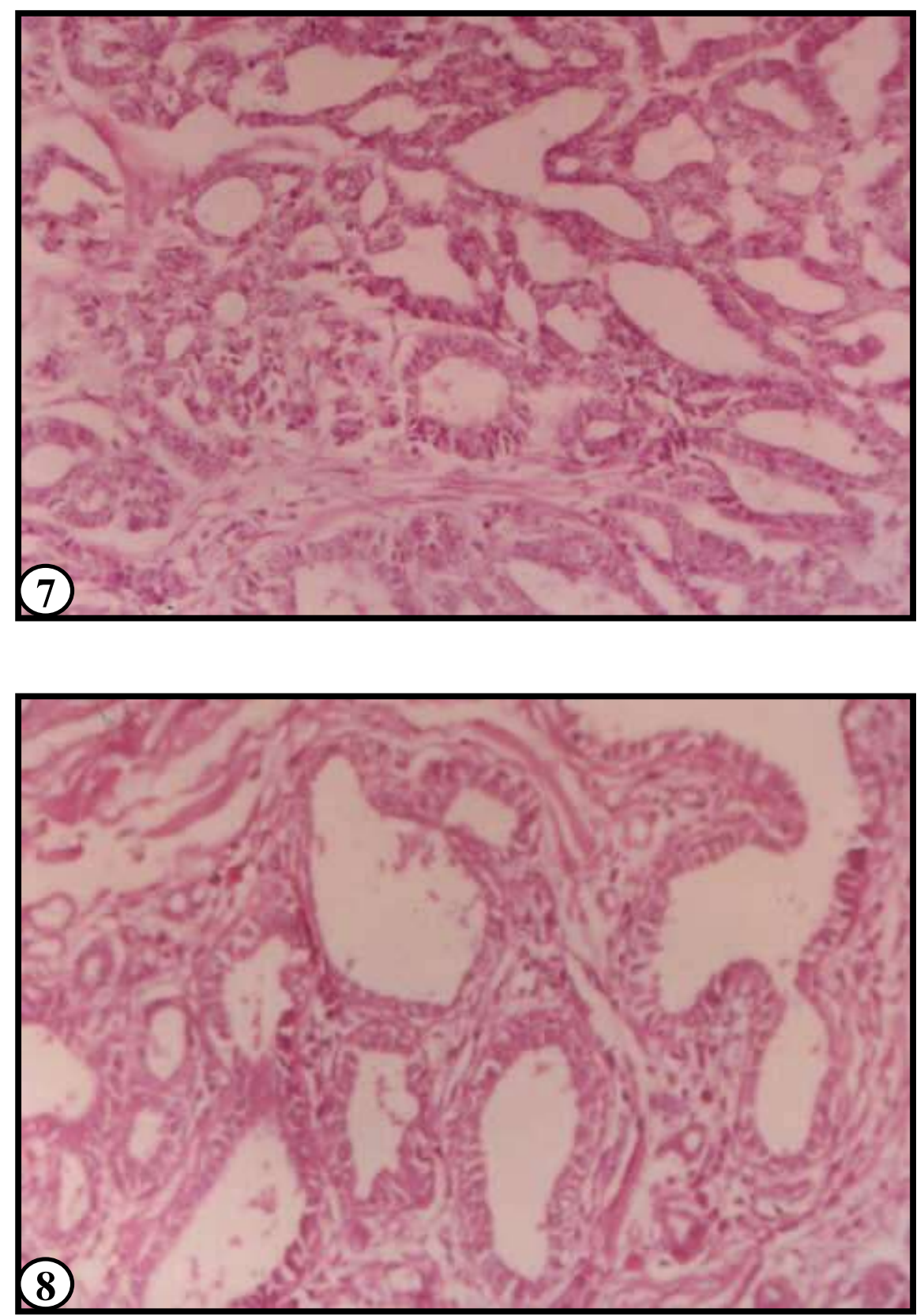

$\overline{\text { Kafr El-Sheikh Vet. Med. J. Vol. } 3 \text { No. } 1 \text { (2005) }}$ 
Eman, A. Abdel-Aziz.
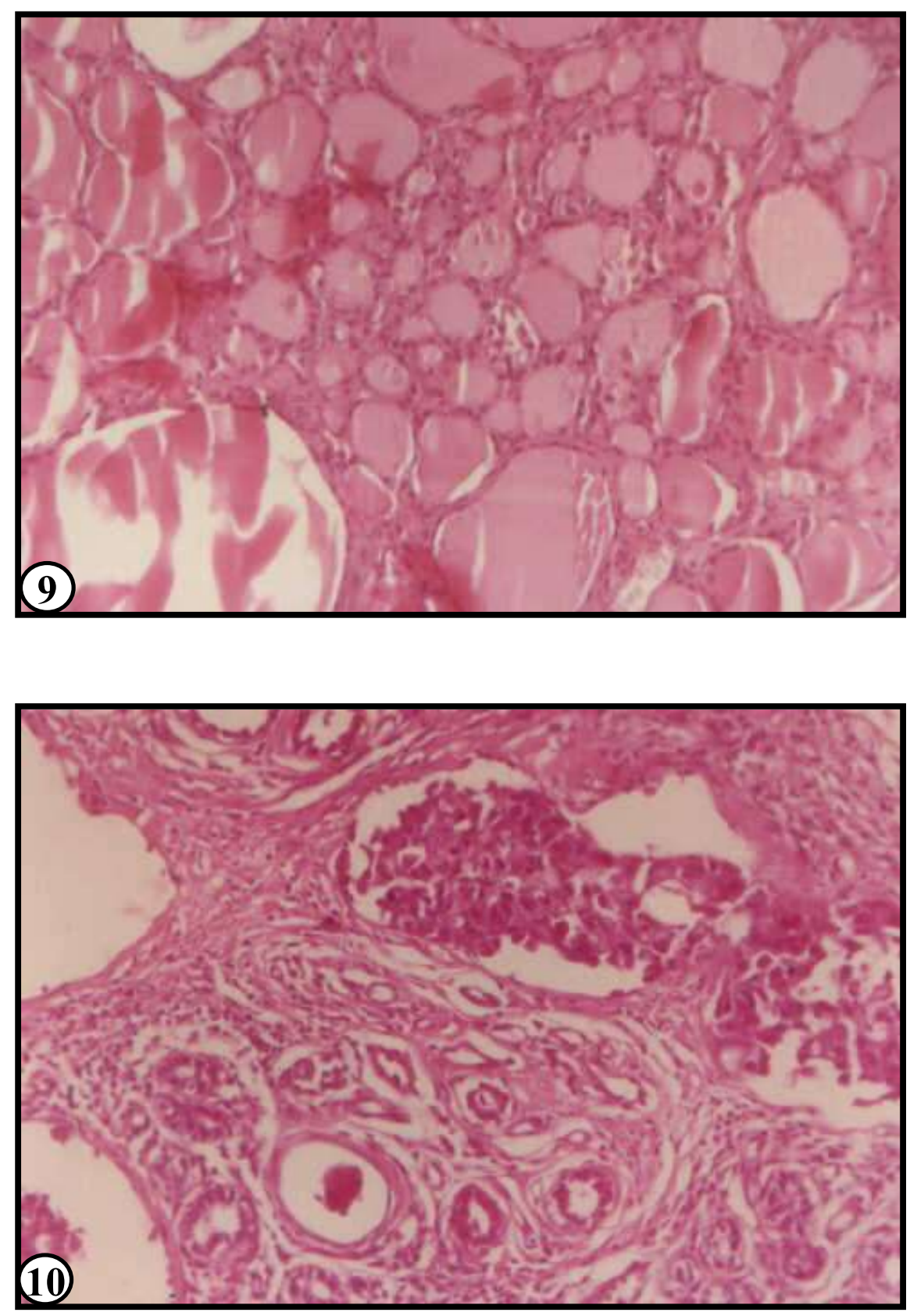

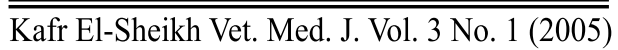



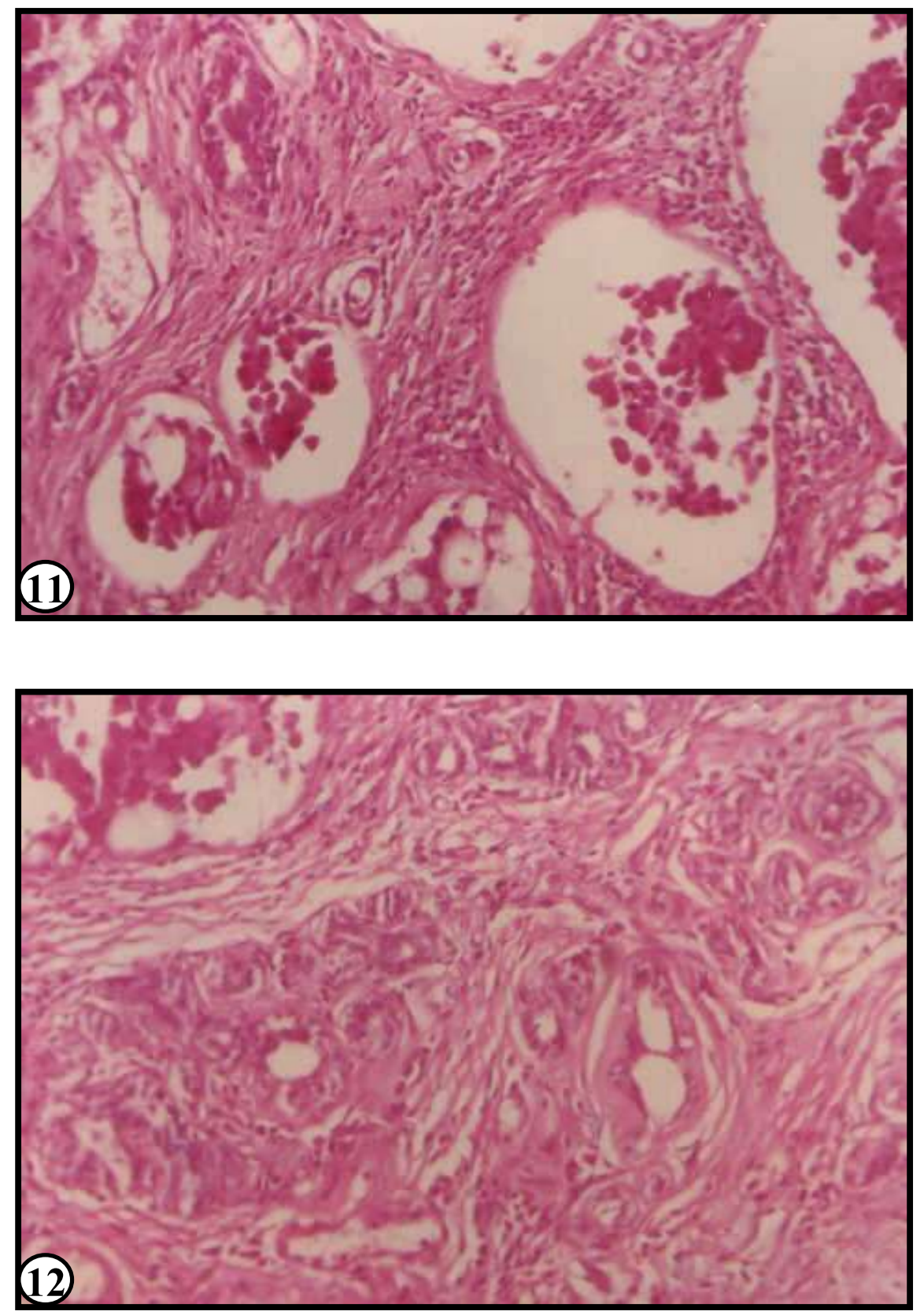

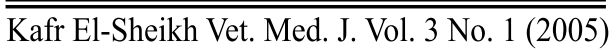



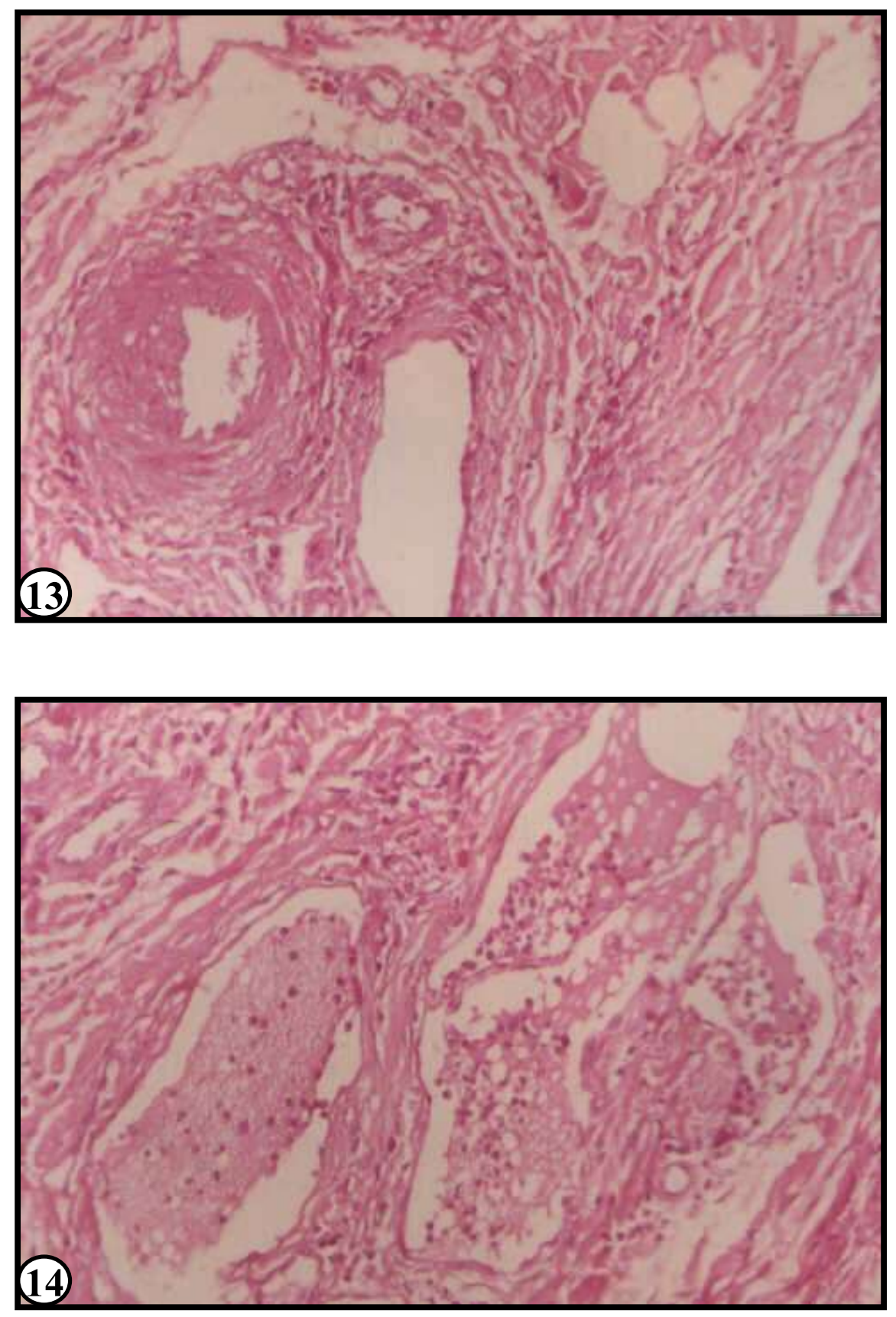

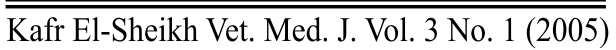



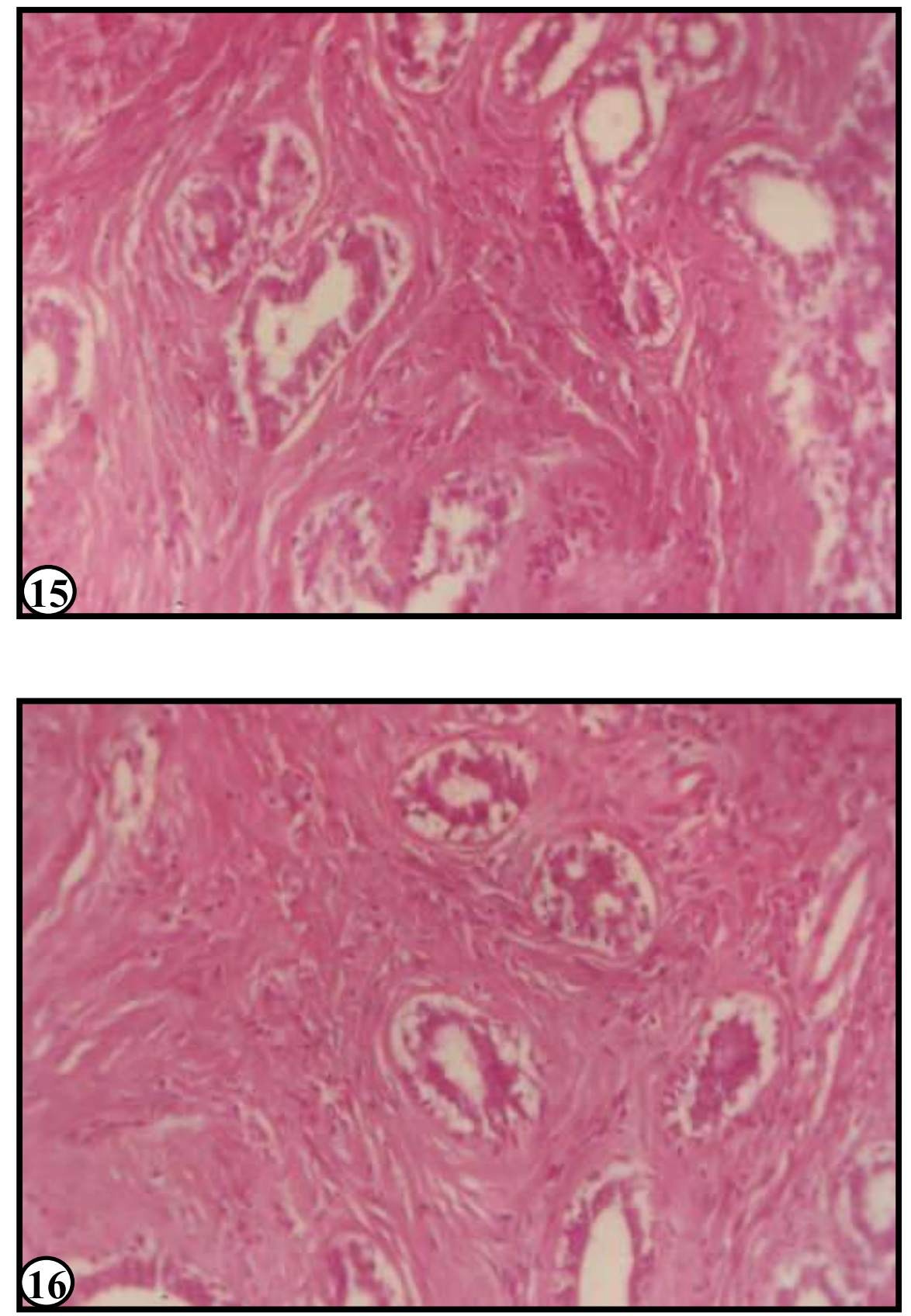

$\overline{\text { Kafr El-Sheikh Vet. Med. J. Vol. } 3 \text { No. } 1 \text { (2005) }}$ 


\section{REFERENCES}

- Bancroft, J.D. and Stevens, A. (1990): Theory and Practice of Histopathol-ogical Techniques.

- Cotchin, E. (1958): Tumors of farm animals: A survey of tumors examined at Royal Veterinary College, London during 1950-1958. Vet. Rec., 73: 816-822.

- D'Arville,C.N.and Pierrepoint,C.G.(1975): The demonstration of estrogen, androgen and progestagen receptors in the cytosol fraction of canine mammary tumors. Eur. J. Cancer, 15: 875-883.

- Dorn,C.R.;Taylor, D.O.N.; Frye, F.L. and Hibbard, H.H. (1968): Survey of animal neoplasms in Alameda and Contra Costa countries, California. (II) Cancer morbidity in dogs and cats from Alameda country. J. Natn. Cancer Inst., 40: 307-318.

- Eskens, V. (1983): Statistical investigation of neoplasm of dogs: Classified according to the WHO recommendation, particularly mammary and skin tumors. Vet. Pathol., 6: 673-679.

- Evans, C.R. and Pierrepoint, C.G. (1975): Tissue steroid interactions in canine hormone-dependent tumors. Vet. Rec., 13: 464-467.

- Hamilton, J.M.; Else, R.W. and Forshaw, P. (1977): Estrogen receptors in canine mammary tumors. Vet. Res., 101: 258-260.

- Jubb, K.V.F.; Kennedy, P.C. and Palmer, N. (1993): Mammary neoplasms of the bitch. J. Nat. Cancer Inst., 62: 1287-1293.

- Lucilia, P. and Nune, S.J.L. (1981): Frequency of tumors among dogs in Mozambique between 1967-1978. Vet. Pathol., 13: 189-194. 
- Monson, K.R.; Malbica, J.D. and Hubbem, K. (1977): Determination of estrogen receptors in canine mammary tumors. Am. J. Vet. Res., 38: 1937-1939.

- Motel, J.A.; Selman, P.J.; Sprang, E.P.; Van Neck, J.W. and Oosterlaken-Dijksterhuis, M.A. (1997): The role of progestins, insulin like growth factor (IGF) and IGF binding proteins in the normal and neoplastic mammary gland of the bitch. J. Reprod. Fert. Suppl., 51: 339-344.

- Owen,L.N.(1979): A comparative study of canine and human breast cancer. Invest. Cell. Pathol., 2: 257-275.

- Penazze, C.; Marcato, P.S. and Piaciani, A. (1989): Lesions associated with mammary neoplasm in dogs and cats. Bollottino Associazion Italiano Vet. Perpiccoli Animali, 28: 245-252.

- Porle,L.;Mialot, J.P.; Lagneau, F. and Parodi, A.L. (1980): Canine mam-mary tumors: An experimental model for the study of hormone dependence of mammary carcinoma. Cancer Treatment Reports, 63: 1169-1174.

- Raynaud, M.J.; Cotard, M.; Andre, F.; Mialot, J.P. and Rolland, P.H. (1981): Spontaneous canine mammary tumors: A model for human endocrine therapy. J. Steroid Biochemistry, 15: 201-207.

- Strandberg, J.D. and Goodman, D.G. (1974): Animal model of human disease. Breast cancer. Animal model: Canine mammary neoplasia. Am. J. Pathol., 75: 225-228.

- Yancher,I.; Encher, S.; Tashe, V.S. and Tsvtkov, Y.A. (1988): Pathology of spontaneous mammary neoplasms of dogs in Bulgaria. Obshchi,Sravnitelna Pathologiya, 24: 12-16. 